\title{
TRADUZIR A POESIA SONORA
}

\author{
Olga Kempinska \\ Universidade Federal Fluminense \\ Niterói, Rio de Janeiro, Brasil
}

\begin{abstract}
Resumo: Relacionada enquanto efeito aos momentos-chave da encenação da emergência da linguagem, intensamente permeada pela afetividade, a meio-caminho entre o verbal e o pré-verbal, a poesia sonora é, sem dúvida, uma das maiores tentações de um tradutor de poesia. Ela se torna também um dos seus casos-limite. O presente trabalho procura apresentar e discutir a teoria da tradução da poesia sonora tal como conceituada por Roman Ingarden. Tomando como exemplos algumas das práticas poéticas das vanguardas e algumas soluções propostas por Augusto e Haroldo de Campos no Panorama de Finnegans Wake, analiso a noção ingardeniana de quase palavra e a diferença que existe entre a fruição da obra literária e a apreciação da obra musical. O interesse pela tradução não se limita para o pensador polonês à análise teórica: ele surge em meio ao seu trabalho filosófico, que se destaca pelos aspectos marcadamente bilíngues. De fato, na formulação da sua estética fenomenológica a tradução do polonês para o alemão (e vice-versa) participa do próprio processo do pensamento criativo. Palavras-chave: Tradução poética; Poesia Sonora; Roman ingarden
\end{abstract}

\section{TRANSLATING SOUND POETRY}

\begin{abstract}
Linked as effect to key moments of the mise-en-scène of the language's origins, intensely permeated by the affectivity, in the middleway between the verbal and the preverbal, the sound poetry surely is one of the major temptations to a translator of poetry. It also becomes one of his limit-cases. This paper aims to present and discuss the theory of the sound poetry's translation conceived by Roman Ingarden. Taking as examples some of vanguard's practices, as well as some of solutions by Augusto and Haroldo de Campos in Panorama de Finnegans Wake, I analyze the
\end{abstract}


Ingarden's notion of quase word and the difference between the fruition of the literary work and the appreciation the musical work. The interest in translation is not restraint for the Polish thinker to theoretical analyses, having its origin in his philosophical work distinguished by its strong bilingual aspects. In fact, in the formulation of his phenomenological esthetics the translation from Polish to German (and vice-versa) takes an important part in the very process of creative thinking.

Keywords: poetic translation. sound poetry. roman ingarden

Em seu trabalho inovador $A$ obra de arte literária (Das literarische Kunstwerk), escrito em alemão entre 1927 e 1931, e traduzido para o polonês apenas em 1960, Roman Ingarden (1893-1970) lançou os fundamentos da estética da recepção, definindo a obra literária do ponto de vista fenomenológico. Com efeito, situada entre a materialidade objetiva do texto e a subjetividade da consciência leitora, a obra surge como bidimensional e multistratificada. Sua construção bidimensional corresponde à articulação horizontal do movimento da leitura do início até o fim, ou seja, à temporalidade da fruição. Quanto à multistratificação da obra, esta remete, segundo o fenomenólogo empenhado em descrever a reciprocidade da relação da fruição-constituição, à articulação das estruturas textuais na consciência leitora a partir de quatro estratos. $\mathrm{O}$ estrato das formações fónico-linguísticas envolve palavras em seus aspectos sonoros, rítmicos e de imagens acústicas, desempenhando, como veremos, um papel muito importante no que tange à participação das emoções na recepção. O estrato das unidades de significação remete à produção de sentidos de palavras e de frases, ao passo que o estrato das objetividades apresentadas se relaciona à formação de objetos representados e de suas relações, permitindo, assim, a constituição dos temas. Finalmente, o estrato dos aspectos esquematizados estimula uma atualização na consciência leitora do mundo representado, configurando-se de maneira bastante descontínua e permitindo o surgimento dos lugares vazios, que correspondem aos momentos de resistência à constituição do sentido e, com isso, à experiência de uma intensificação do desempenho imaginativo por parte do leitor. É preciso sublinhar que, na visão de Ingarden, 
essas duas dimensões e esses quatro estratos, quando articulados na consciência do leitor, seguem os desdobramentos complexos, multifários e entrelaçados, evitando, com isso, uma ordenação hierárquica simples.

É justamente a partir da visão da obra literária enquanto uma virtualidade situada no espaço fenomenológico entre texto e leitor que Ingarden formula em 1955, uma interessante reflexão acerca da tradução, que retoma algumas das dúvidas colocadas duas décadas mais cedo, em $A$ obra de arte literária. Como veremos, estas dúvidas dizem respeito aos incertos limites do domínio do literário e do estético. De fato, no trabalho "Sobre traduções"1 o filósofo polonês compara os desafios tradutórios de uma obra científica com aqueles que se apresentam ao tradutor de uma obra literária, contemplando ainda, na parte final, os problemas específicos da tradução de textos filosóficos. Cabe ressaltar que o interesse pela tradução no pensamento estético de Ingarden não se limita à indagação teórica: ele surge em meio ao seu trabalho filosófico, que se destaca pelos aspectos marcadamente bilíngues. Aluno de Husserl e professor da Universidade de Cracóvia (UJ), o filósofo publicava seus "originais" ora em polonês ora em alemão, praticando também autotradução, que frequentemente levava a significativas reformulações das suas propostas "originais".

Além de se manifestarem em diferentes versões de seus ensaios, os traços do bilinguismo de Ingarden deixam-se perceber, e quem sabe, até melhor, no seu curso de estética de 1960. Ofertado em polonês e transcrito a partir de anotações dos participantes, o curso preserva as características da oralidade, preciosas para a observação da formulação do pensamento de Ingarden. Logo nas primeiras aulas fica claro que a tradução dos conceitos faz parte do processo de sua apresentação e de sua explanação. Nesse fascinante bojo reflexivo não são raros os casos de combinações translíngues, nas

${ }^{1}$ Existe uma tradução desse texto para o inglês. Cf. TYMIENIECKA, Anna-Teresa. Ingardeniana III. Roman Ingarden's Aesthetics in a New Key and the Independent Approaches of Others: The Performing Arts, the Fine Arts and Literature. Dordrecht: Kluwer Academic Publishers, 1991, pp. 131-192. 
quais as palavras das duas línguas se procuram mutuamente, encenando curiosos momentos de frutíferos desencontros: "A saber, aquela Deutung, ou, antes, das Gedeutete, aquilo que é introduzido pela nossa interpretação" (INGARDEN, 1981, p. 51). Nas fascinantes aulas de Ingarden, que versam sobre os meandros da estética fenomenológica, tampouco são difíceis de encontrar comentários explícitos acerca da dificuldade da tradução, e, assim, por exemplo, sobre a palavra "Genuss", Ingarden assinala: "é uma palavra muito difícil de ser traduzida em polonês, significando literalmente 'rozkosz'. Mas essa não é a tradução certa (...)" (INGARDEN, 1981, p. 43). Acerca da conhecida expressão "Einfühlung”, o filósofo chega a esboçar a possibilidade de uma duvidosa tradução dupla: "Como já falei, é difícil traduzir em polonês a palavra 'Einfühlung', uma vez que se impõem aqui duas possibilidades linguísticas que, no entanto, apontam para dois diversos elementos de conteúdo" (INGARDEN, 1982, p. 46). Surgem finalmente também algumas expressões que parecem apresentar a resistência absoluta à tradução, tal como, por exemplo, alguns dos vocábulos do repertório utilizado por Robert Vischer para significar as diversas matizes da comunhão de sentimento. Nesta aula, que confronta Ingarden com os limites do traduzível, revela-se não apenas o quanto o filósofo estava familiarizado com as teorias da tradução, mas também que sua sensibilidade de tradutor levava em consideração a transposição de elementos morfossintáticos:

Além disso, ele lança mão de termos alemães bastante artificiais; alguns tornaram-se correntes, mas é muito difícil traduzi-los em polonês, e então, deixem que eu cite esses termos, tentando interpretá-los de alguma maneira. Assim, ele fala não apenas de miterleben, mitfühlen - este é o momento introdutório do processo todo, mas também de anfühlen, nachfühlen, zufühlen. $\mathrm{O}$ que significam os prefixos an, nach, zu? An e zu envolvem em seu significado algo próximo de "lançar sob um objeto"; anfühlen e zufühlen remetem então a algo parecido e, contudo, existe 
uma certa diferença linguística que não sei transpor em polonês. Quanto a nachfühlen, este termo tornou-se corrente na língua alemã e sobretudo mais tarde, no século XX, numerosas vezes surgirá a questão de Nacherleben: não é possível, dizem, traduzir um poema lírico, mas é possível fazer sua Nachdichtung, ou seja, é possível escrever um outro poema, no qual se dá algo como uma recriação ou uma imitação do primeiro, de certa forma repetindo-o, mas com originalidade - e isso também terá seu valor. (INGARDEN, 1981, p. 65)

Todos esses exemplos mostram que, na elaboração da obra filosófica de Ingarden, a tradução participa direta e intimamente do próprio processo do pensamento criativo, e que sua reflexão teórica acerca dos tipos e das dificuldades da tradução, que não deixa de contemplar os desafios da tradução do estilo de um filósofo, surge de uma longa e rica prática. Neste percurso de várias décadas, contemporâneo de violentas mudanças geopolíticas que conflagraram as fronteiras do Leste Europeu, o polonês e o alemão, o domínio teórico e o domínio prático, a escrita e a oralidade, e, também, o estético e seus problemáticos confins, formam um campo denso, tenso e complexo, enfim, propício à formulação de questões.

Sem cometer a imprudência de transformar a dificuldade da tradução poética em um caso hierarquicamente elevado acima da tradução de outros tipos de textos, por exemplo, científicos ou filosóficos, Ingarden procura descrever os problemas peculiares encontrados na transposição do "estético". De fato, o desafio específico da tradução da obra literária tange à exigência de se despertar no leitor "uma experiência estética particular, multifasal e muito complexa, na qual os elementos emocionais predominam sobre os outros" (INGARDEN, 1972, p. 122). Segundo a visão ingardeniana, traduz-se então não o "texto", tampouco a mensagem do autor, mas, antes, o efeito da obra em toda sua riqueza e complexidade, tal como descrita em $A$ obra de arte literária. Insistindo na necessidade de tornar possível, na obra traduzida, a atualização 
de um efeito estético comparável, Ingarden insiste também na extrema dificuldade da tradução do estrato fónico-linguístico, que, longe de consistir simplesmente em sonoridades das palavras, vêse diretamente relacionado à emergência do sentido, envolvendo as qualidades rítmicas e condicionado a determinação afetiva das representações.

Nem é preciso dizer o quanto a extrema importância do estrato fónico-linguístico o torna fascinante e vulnerável enquanto objeto de tradução. Pois trata-se do elemento da obra no qual o teor lírico adquire a saturação máxima, correndo com isso o risco de explodir os limites daquele domínio que aparentemente afirma. Esse paradoxo parece ter exercido uma atração especial no filósofo. De fato, na parte final de $A$ obra de arte literária, Ingarden havia dedicado uma atenção especial à análise dos casos-limite, daqueles "casos duvidosos cuja singularidade e inclusão nas obras literárias (ou obras de arte) não nos eram de começo evidentes" (INGARDEN, 1973, p. 347). Como exemplos dessas manifestações dificilmente classificáveis o pensador indica a peça de teatro, o espetáculo cinematográfico, a pantomima e a obra científica. Essa lista inicial dos casos limítrofes, particularmente significativos por serem desafiantes para a reflexão sistemática, ganha posteriormente mais um elemento: o poema sonoro. De fato, em um ensaio de 1947, Ingarden debruça-se mais detalhadamente sobre a especificidade do efeito estético da poesia na qual as palavras sofrem consideráveis deformações.

Cabe ressaltar que o principal interlocutor de Ingarden é nesse ensaio um poeta, Julian Tuwim (1894-1953). Tradutor de Puchkin, mas também de Whitman, Tuwim exacerbava em seus poemas, aparentemente muito simples, a sensualidade dos efeitos sonoros. Um dos seus numerosos poemas que encenam o gozo com a sonoridade das palavras chega a entremear a materialidade do nome do poeta com a textura dos versos, de modo a sugerir a iminência da dissolução subjetiva na "relva": 
Trawa

Trawo, trawo do kolan!

Podnieś mi się do czoła, Żeby myślom nie było

Ani mnie, ani pola.

Żebym ja się uzielił,

Przekwiecił do rdzenia kości

I już się nie oddzielił

Słowami od twej świeżości.

Abym tobie i sobie

Jednym imieniem mówił:

Albo obojgu - trawa,

Albo obojgu - tuwim.

Relva

Relva até os joelhos!

Vem-me até as celhas,

Que a mente se desvencilhe

De mim, de tudo, ó relva!

E quero me enrelvar Até o tutano em flor, E nunca me separar

Com a palavra de teu vigor.

E o mesmo nome nos une

A ambos, a mesma seiva:

Ora os dois - túwim

Ora os dois - relva.

(TUWIM, 1990, p. 44. Tradução minha) 
Tradutor de poesia russa (Pushkin, Lérmontov, Blok, Maiakovski), francesa (Rimbaud), alemã (Heine) e latina (Horácio), uma das figuras de proa da vanguarda polonesa, Tuwim, além de escrever poesia sonora e non-sense, na qual despejava algo do seu aguçado senso de humor, chegou a traduzir poesia polonesa para 0 esperanto. O talento linguístico de Tuwim foi bem descrito em um recente ensaio: "sabia várias línguas, ainda que não se considerasse um poliglota" (GLIŃSKI, $2013 \mathrm{~s} / \mathrm{p}$ ). E foi a partir da efervescência da sua paixão pelas línguas que Tuwim chegou a formular uma reflexão utópica acerca dos efeitos das palavras musicais libertas das relações referenciais. Seduzido e provocado, Ingarden, de fato, cita, discute e, como veremos, acaba por criticar uma opinião de Tuwim acerca do uso sonoro das palavras:

\begin{abstract}
Aqui as palavras ficam libertas de todas as relações com a realidade ou com a realidade irreal. As palavras existem por elas mesmas e para elas mesmas, e nós podemos inscrever em seus sons, tal como nas notas musicais, os textos de nossas emoções e representações, ou aspirar a pura eufonia, cujos elementos aliteracionais crescem junto com o ritmo do poema, resultando em um evento estético a dois estratos. "Sentido", "conteúdo" - esses já formariam a terceira dimensão (Apud. INGARDEN, 2000, p. 93).
\end{abstract}

Nas palavras de Tuwim ressoam não apenas os ecos do futurismo italiano, das violentas práticas dadaístas e da inspirada poesia transmental russa: em sua valorização da eufonia faz-se também ouvir algo dos postulados da geração precedente dos simbolistas, por exemplo, daqueles realizados nos poemas de Verlaine, cujo tradutor procurou recentemente fazer jus ao vertiginoso movimento "entre os extremos da linguagem" (Apud. VERLAINE, 2011, p. XI), assinalado no início do século passado por Valéry. A injunção à musicalidade dos versos atingiu, de fato, um dos seus ápices em Mallarmé, que propôs uma poética baseada na exigência de se estreitar os laços entre palavra e música a ponto de se tencionar ao 
máximo o jogo da referencialidade: "musicalmente levanta-se, a ideia mesma e suave, a ausente de todos buquês" (MALLARMÉ, 1998, p. 198).

Fruto da fruição dos efeitos desnorteantes das poéticas pós-românticas, o momento de controvérsia particularmente instigante no texto de Ingarden diz respeito justamente à relação entre o domínio linguístico e o domínio sonoro: o filósofo não concorda de todo com Tuwim quanto à possibilidade de se ler as palavras de um poema apenas como notas musicais. A comparação exaltada desde a época simbolista pode, com efeito, levar ao reducionismo, deturpando a visão da relação estética despertada pelo poema. Desconfiando e lançando mão da sua visão fenomenológica da fruição, Ingarden pergunta-se em que sentido um poema sonoro, no qual existe uma forte deformação das palavras, poderia ainda ser considerado uma obra literária formada de quatro estratos, e acaba por confirmar que nem nos casos de deformações intensas a obra verbal se confunde por completo com uma obra musical. A insistência na diferença entre a obra literária e a obra musical não resulta da desconsideração dos efeitos desta última. Ao dedicar posteriormente, em 1960, todo um estudo à fruição da obra musical, o filósofo não deixa de assinalar que, além de seus fenômenos elementares, a saber, as qualidades sonoras, a música envolve também "diversos tipos de qualidades e formações de natureza não sonora" (INGARDEN, 2005, p. 66), tais como sua estrutura quase-temporal, seu "movimento" responsável pela criação do espaço sonoro, "formas" musicais e qualidades emocionais. Ainda assim, quando examinados com rigor, os efeitos da obra musical resultam ser muito diferentes dos de um poema sonoro:

A função de representação realizada pelos motivos musicais que representam sem auxílio de elementos linguísticos é fundamentalmente distinta da função de representação realizada em uma obra literária pelas formações linguísticas. As palavras, as expressões e as frases realizam essa função pelo fato de serem dotadas de significado, de 
sentido conceitual, por assim dizer. Os sons das palavras são portadores de intenções de significação e, enquanto tais, designam certos objetos com uma constituição formal correspondente e com seus atributos qualificativos (p. ex. coisas, processos, eventos), em função do conteúdo de seu significado. (...) entre os motivos representacionais da música programática e as formações linguísticas ocorre uma diferença fundamental, baseada principalmente no fato dessas primeiras representarem graças a sua semelhança com o objeto representado - donde a limitação do domínio daquilo que pode ser assim representado -, ao passo que as formações linguísticas não exigem semelhança alguma entre o som da palavra, seu sentido e o objeto representado, e em nada lhes auxilia uma tal semelhança. Essa diferença fica até certo ponto embaçada nas formações tão liminares e excepcionais como, por exemplo, Stopiewnie de Tuwim (...). (INGARDEN, 2005, pp. 86-87)

Ainda que, como diz Ingarden, a distinção entre a música e a linguagem verbal fique menos nítida no caso da poesia sonora - e o nome dado pelo Tuwim a suas práticas poéticas, Stopiewnie, é uma curiosa montagem dos vocábulos stowo ("palavra") e piewać ("trovar"), trazendo também ecos da palavra stowik ("rouxinol”), um neologismo que dá, portanto, as boas-vindas à confusão poética -, uma obra literária não pode ser reduzida a uma obra musical. É verdade que tanto a forma linguística quanto a forma sonora evoluem no tempo e que sua apreensão envolve a protensão, ou seja, o próprio reconhecimento da forma remete em ambos casos à capacidade de se "prever de modo eficaz os elementos por vir" (NOËL, 1996, p. 138). Apesar desse traço em comum, os elementos e os efeitos dos dois tipos de forma, a linguística e a sonora, são distintos. Ao afirmar a diferença entre os dois domínios, Ingarden afasta-se da visão radicalmente onomatopaica da linguagem, próxima da palavra extática que fascinou os adeptos russos do zaum, segundo a qual a linguagem poética - tal como praticada também na "palavra-trovão" de Joyce, em um poema de Ball, de Schwitters 
ou de Marinetti - imitaria apenas pelo som, sendo comparável enquanto efeito a uma língua estrangeira desconhecida: “As línguas estrangeiras também são música, quando o ouvinte não compreende nada de seu significado" (SCHAFER, 2011, p. 228).

Se tal fosse o caso, não haveria necessidade de tradução.

É verdade que a palavra-trovão não fora traduzida na versão brasileira do Finnegans Wake, mas isso não porque ela seja simplesmente onomatopaica, mas, antes, pelo fato dela consistir em uma impressionante montagem babélica de várias línguas, inclusive do português, que parece encenar o próprio processo de sua tradução: "bababadalgharaghtakamminarronnkonnbronntonnerronntuonnthunntrovarrhounawnskawntoohoohoordenenthurnuk!" (CAMPOS, 1971, p. 35). Por outro lado, inúmeras outras palavras e expressões sonoras, tais como "riverrun", "riocorrente", ou "doublin their mumper", "dublando os bebêbados" (CAMPOS, 1971 , p. 35), foram, sim, traduzidas pelos irmãos Campos. Observemos que muitas invenções joycianas guardam na versão brasileira algo de sua estrutura "original", sendo, ao mesmo tempo, modificadas do ponto de vista da morfologia. É justamente dessa maneira que elas se adequam ao espírito da língua brasileira: "unuchorn" - "unucorno", "ungulant" - "ungulante", "uvuloid" - "uvulóide", "uskybeak" - "uisquisito" (CAMPOS, 1971, pp. 40-41).

Com efeito, segundo Ingarden, as palavras deformadas de um poema sonoro não podem ser fruídas como meros sons. Elas são chamadas pelo filósofo polonês de "quase palavras", ou seja, de formações que "se fingem" (INGARDEN, 2000, p. 91) de palavras. Vale a pena ressaltar que, embora se trate de "quase palavras", estas não deixam de pertencer a uma língua de fato existente, e que, para que o processo de fingimento funcione, a própria deformação deve obedecer às regras morfológicas e às regras de pronúncia da língua em questão. Como nas diversas antropologias da ficção, o regime do ficcional não se opõe na proposta de Ingarden ao regime da realidade, constituindo-se, antes, em um domínio de um jogo recíproco.

De fato, as "quase-palavras" jogam com as palavras. Assim, o efeito que elas produzem no leitor não é o de uma língua estran- 
geira desconhecida: trata-se, antes, da impressão da língua própria "quase" desconhecida; ou "quase" conhecida. Como explica Ingarden, no processo da transformação das palavras existentes, as sonoridades às quais não corresponde sentido algum, não deixam, no entanto, de sugerir sentidos de palavras existentes. As formações que se fingem de palavras de um determinado tipo linguístico criam qualidades fónico-linguísticas características da língua em questão e, dessa maneira, elas "produzem a impressão" (INGARDEN, 2000, p. 91) de uma autêntica sequência de palavras, na qual aparecem, aliás, de vez em quando, palavras muito parecidas com as existentes ou até mesmo palavras existentes de fato. No caso dos poemas, o processo do fingimento é, segundo Ingarden, ainda reforçado pela versificação e pelo ritmo. Nesse processo da deformação sistemática e ordenada o estrato fónico-linguístico adquire uma preponderância especial, ao passo que os três estratos restantes não são simplesmente anulados, mas, antes, existem e funcionam em um estado seminal, formando uma "nebulosa" (INGARDEN, 2000, p. 94) de um mundo representado, fortemente marcada pela atmosfera emocional. Assim, criticando a visão radicalmente formalista da linguagem poética, Ingarden atribui aos poemas transmentais um lugar limítrofe no domínio da literatura.

Se, como afirma Lévi-Strauss, "a música exclui o dicionário" (2010, p. 71), aqueles que fazem e que traduzem a poesia sonora, non-sense e transmental não raramente são amantes dos dicionários: basta pensarmos na tradução de Ulisses por Houaiss, na prodigiosa competência de Tuwim, nas incursões linguísticas dos irmãos Campos; ou nos entusiasmos linguísticos e tradutórios de Leminski, autor de Catatau. A poesia sonora confirma a tremenda importância do estrato fónico-linguístico, e as "palavras", que Ingarden coloca entre aspas, ao perturbarem o processo de significação, afetam o funcionamento dos três estratos restantes. $\mathrm{O}$ fato de existir no estado seminal, acaba por investir esses estratos de uma intensidade específica. Talvez o mais interessante seja aqui o fato de que, para descrever o efeito das "palavras", o filósofo tenha laçado mão de uma metáfora cósmica: 
(...) dotadas de certas características emocionais, as estruturas sonoras não designam uma situação concreta ou determinada, tampouco eventos ou objetos representados como é o caso da obra literária em sua acepção restrita -, somente um núcleo de nebulosa (mgtawicowa zaródź) dessas situações, um mundo emergente, mas nunca de fato nascido, volátil e passageiro, e que deixa um eco emocional na alma do "leitor" apenas por meio de sua atmosfera afetiva. (INGARDEN, 2000, p. 94)

A bela metáfora cósmica "núcleo de nebulosa" poeticamente expressa as diversas características do efeito das "palavras", inseparável do ambivalente efeito do "quase": sua intensidade e sua indeterminação; seu poderoso potencial de criação; sua permanência no estado seminal; seu inacabamento constitutivo; a esperança, senão o anseio (o uso das metáforas cósmicas em 1947 estava ainda envolvido no contexto discursivo da promessa); sua inatingível sublimidade, quem sabe. No seu curso de estética de 1960, ao investigar a maneira de existir do objeto estético em sua relação com a imaginação do fruidor, Ingarden assinala que "uma quase-presença é necessária para que haja apreciação. A capacidade de se atualizar na arte aquilo que não existe - eis a arte" (INGARDEN, 1981, p. 27). Quase-palavra, quase-sentido, quase-linguagem, quase-música, o efeito da poesia sonora por pouco não se confunde com o cerne do estético.

Uma vez que a criação de quase palavras se dá com base em processos morfossintáticos de uma língua, as palavras preservam relações de sentido com seus elementos: prefixos, radicais e sufixos. Dessa maneira, elas se tornam o lugar privilegiado da encenação dos processos da formação das palavras. No conto de ficção científica de Stanisław Lem sobre uma máquina-poeta os poemas sonoros surgem, de fato, como as primeiras produções. Considerados pelos construtores ainda imperfeitos, os balbucios tornam, contudo, possível a produção de poemas "de verdade". A primeira realização linguística da máquina, "chrzeskrzyboczek pacionkocie- 
wiczarokrzysztofoniczny" (LEM, 1975, p. 138), composta de dois monstruosos polissílabos, apesar de ser excessiva e surpreendente, resulta perfeitamente pronunciável em polonês, ao passo que, devido às estruturas fonéticas do português e aos hábitos fonéticos dos brasileiros, que, por exemplo, não estão acostumados a pronunciar sequências de consoantes - tais como "chrz" -, e que tampouco conhecem a pronúncia dos dígrafos "ch", "rz" ou "cz", familiar aos poloneses, os polissílabos da máquina de Lem são bastante penosos na hora da leitura em voz alta. O leitor brasileiro procura por soluções no sistema fonético do português, pronunciando o dígrafo "ch" como [] (e não como [h], aspirado, como é o caso em polonês), e, desconsiderando os dígrafos, lê separadamente as consoantes. Assim, o núcleo da nebulosa de um sentido emergente não se produz. Analisemos então brevemente esse núcleo acessível apenas àqueles que compreendem o polonês. Como diz Ingarden, trata-se de uma experiência volátil e passageira da encenação de um movimento deliciosamente inacabado e instável. "Chrzęskrzyboczek" remete em polonês aos quase sentidos de "crepitar" e de "besouro" (pelo verbo "chrześcić" e pelo substantivo "chrzaszcz"), de "ranger" (pelo verbo "skrzypieć"), de "cruz" e de "curva" (pelo morfema "krzy" que inicia as palavras "krzyż", "cruz", e "krzywa", "curva"). O polissílabo faz também pensar vagamente em um trava-língua praticado em um conhecido poema para crianças escrito por Jan Brzechwa (Cf. en[fr,es]/wikipedia/.org/wiki/chrząszcz).

Relacionada enquanto efeito à encenação da emergência da linguagem, fortemente permeada pela afetividade, a meio-caminho entre o verbal e o pré-verbal, a poesia sonora não deixa de ser uma das maiores tentações de um tradutor de poesia. O próprio Ingarden conclui seu ensaio dizendo que compreender os efeitos e a natureza dos poemas sonoros "possui uma grande importância não apenas para na teoria da arte literária, mas também para a teoria da linguagem e a teoria do conhecimento" (INGARDEN, 2000, p. 96). Não estranha então que o mais notável poema non-sense da língua inglesa, o "Jabberwocky", tenha suscitado uma verdadeira febre tradutória: como nota Martin Gardner, "deve haver 
pelo menos 50 diferentes versões de 'Jabberwocky' em 50 línguas diferentes” (CARROLL, 2000, p. 147). Impressionante é aqui não apenas o número, mas também o movimento da proliferação incontrolável de traduções rivais. O lugar limítrofe da poesia sonora não raramente resulta em uma instabilidade genérica dessa produção, e muitos dos poemas de Carroll e de Tuwim, ao encenarem ludicamente a emergência da linguagem, encontram seu lugar (também) na estante da literatura infantil. O "Jaguardarte", traduzido por Augusto de Campos junto com fragmentos de Joyce e publicado em apêndice do Panorama do Finnegans Wake - que inaugurou, em 1971, a coleção "Signos" da Editora Perspectiva, o evento fulcral da tradução criativa no Brasil -, existe afinal também na versão ilustrada para crianças.

\section{Referências}

CARROLL, Lewis. Aventuras de Alice no País das Maravilhas. Através do espelho. Trad. M. L. X. de A. Borges. Rio de Janeiro: Zahar, 2000.

CAMPOS DE, Augusto e Haroldo. Panorama do Finnegans Wake. São Paulo: Perspectiva, 1971.

GLIŃSKI, Mikołaj. 10 twarzy Juliana Tuwima. 2013. In. http://culture.pl/pl/ artykul/10-twarzy-tuwima. Acesso em 30 de junho de 2017.

INGARDEN, Roman. A obra de arte literária. Trad. A. E. Beau et al. Lisboa: Calouste Gulbenkian, 1973.

INGARDEN, Roman. Wybór pism estetycznych. Cracóvia: Universitas, 2005. 
INGARDEN, Roman. Wyktady i dyskusje z estetyki. Varsóvia: PWN, 1981.

INGARDEN, Roman. Szkice z filozofii literatury. Cracóvia: Znak, 2000.

INGARDEN, Roman. “O Tłumaczeniach”. In. Z teorii jezzyka i filozoficznych podstaw logiki. Varsóvia: PWN, 1972, pp. 120-190.

INGARDEN, Roman. “On Translations”. Trad. J. Wawrzycka. In. TYMIENIECKA, Anna-Teresa (org.). Ingardeniana III. Roman Ingarden's Aesthetics in a New Key and the Independent Approaches of Others: The Performing Arts, the Fine Arts and Literature. Dordrecht: Kluwer Academic Publishers, 1991, pp. 131-192.

LEM, Stanisław. Opowiadania wybrane. Cracóvia: Wydawnictwo Literackie, 1975. Stanistaw Lem Expedição Primeira A ou o poetômato de Trurl. Trad. Olga Kempinska. In. (n.t.) Revista Literária em Tradução 13. Florianópolis, 2017, pp. 174-196.

LÉVI-STRAUSS, Claude. Olhar Escutar Ler. Trad. B. Perrone-Moisés. São Paulo: Companhia das Letras, 2010.

MALlarmé, Stéphane. Poésies et autres textes. Paris: Librairie Générale Française, 1998.

NOËL, Émile (org.). As ciências da forma hoje. Trad. C. K. Moreira. Campinas: Papirus, 1996.

SCHAFER, Murray. O ouvido pensante. Trad. M. Trench de O. Fonterrada et al. São Paulo: Ed. Unesp, 2011.

TUWIM, Julian. Miłość mnie szuka po mieście. Varsóvia: Nasza Księgarnia, 1990.

VERLAINE, Paul. Poems under Saturn. Poèmes Saturniens. Trad. K. Kirchwey. Princeton: Princeton University Press, 2011. 
https://en.wikipedia.org/wiki/Chrz\%C4\%85szcz. Acesso em 23 de outubro de 2016.

https://fr.wikipedia.org/wiki/Chrz\%C4\%85szcz. Acesso em 23 de outubro de 2016.

https://es.wikipedia.org/wiki/Chrz\%C4\%85szcz. Acesso em 23 de outubro de 2016.

Recebido em: 12 de novembro de 2017

Aceito em: 04 de março de 2018 Publicado em: publicado em maio de 2018

Olga Kempinska. E-mail: olgagkem@gmail.com 